\section{[RE] Programar la obsolescencia disección y fragmentos de otras arquitecturas}

[RE] Program obsolescence, dissection and fragments of other architectures

Ángela Carvajal
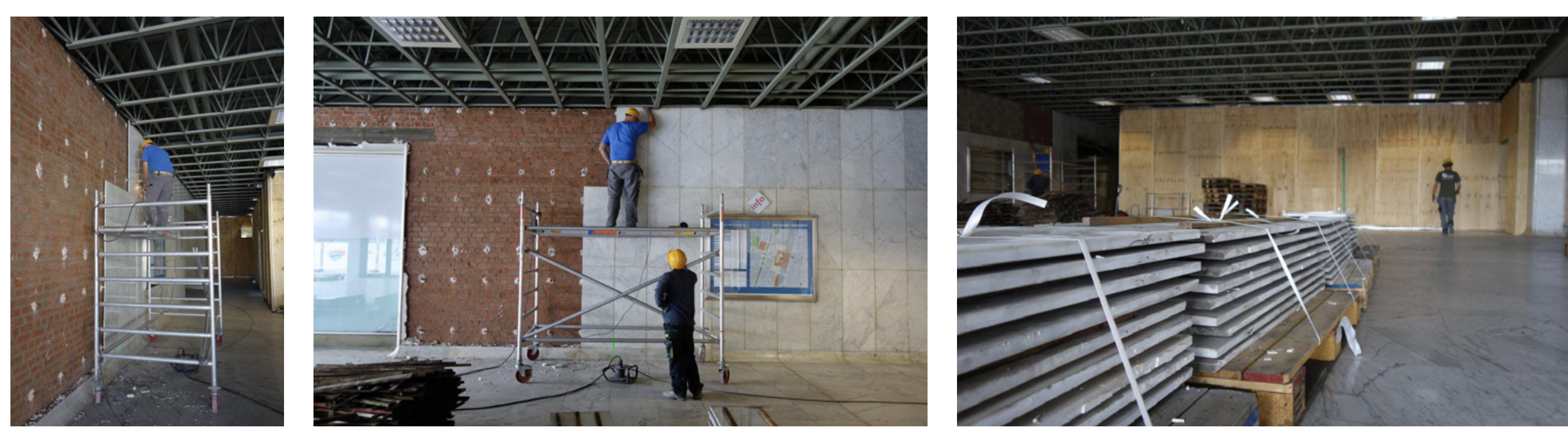

figuras 1,2 y 3
Provecto: Rotor D

Proyecto:Rotor DC: reuse made easy
(Imágenes cortesia de ROTOR, www.
rotordb.org)

Palabras Clave

Obsolescencia

Disección

ROTOR DC

Arquitectura
Resumen La arquitectura se encuentra implícitamente dentro del campo productivo de los sistemas económicos, la obsolescencia dentro de este contexto adquiere como definición la devaluación. La obsolescencia en la disciplina ha sido un tema poco recurrente dado que el enfoque persiste más en el acto de la creación. El presente texto busca debatir sobre cómo las etapas finales asociadas al detrimento de una obra pueden ser los inicios de otras, cómo algunas referencias desde el arte y la arquitectura nos dan atisbos sobre el proyecto de re-programar la obsolescencia como atributo de diseño. 
de arquitecturas en obsolescencia permiten cuestionar el modo de producción disciplinar en cuanto a lo construido en un contexto mundial de recursos materiales limitados. Proyectar la obsolescencia implica desmontar, reciclar y diseccionar en fragmentos la escala de una edificación a la escala material. Planificar el desmantelamiento supone tiempos proyectuales para la caducidad de una obra donde el trabajo artesanal con precisión de tratar cada pieza permite pensar a su vez en su posible futuro. Por lo tanto, cuestionar la obsolescencia también implica su re-programación y su re-significación: el conjunto en piezas y componentes arquitectónicos sustraídos se recontextualizan para otorgarles un nuevo ciclo de vida, aquello que fue creado para un propósito en contextos y épocas determinadas, pueden posteriormente ser utilizados en entornos completamente opuestos, despojando así la carga ideológica e intelectual para utilizarlos con un fin de pragmatismo puro. ¿Cómo proyectar la obsolescencia contemporáneamente? Prácticas actuales como la oficina Rotor de Bruselas nos permiten trazar una línea o por lo menos, abrir cuestionamientos y maneras de operar.
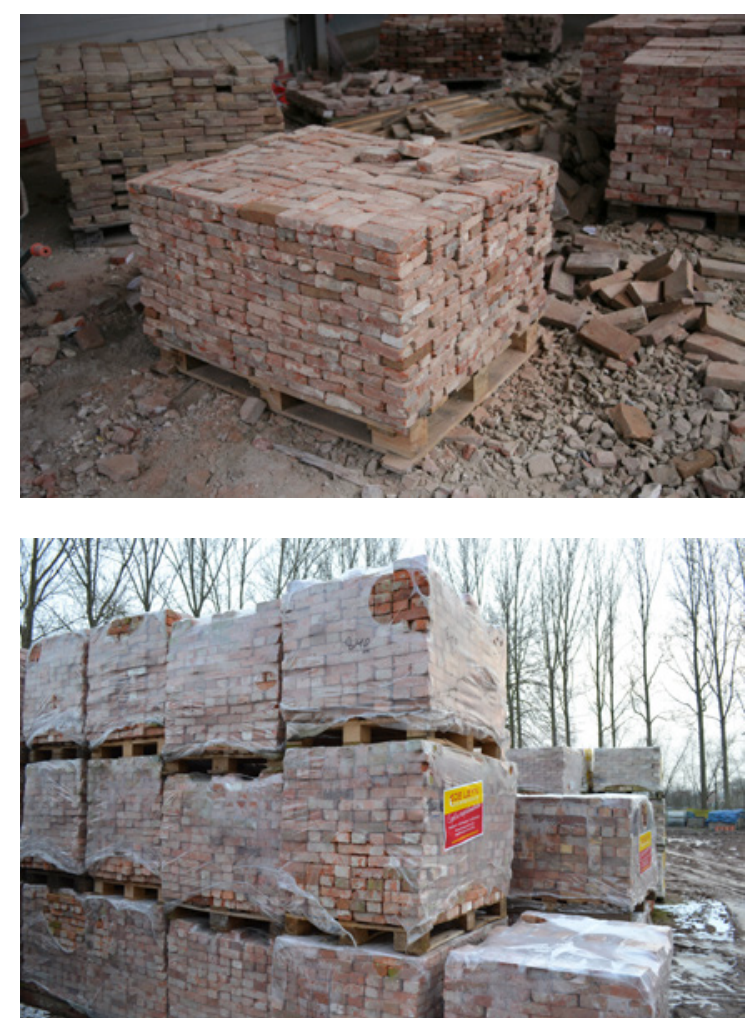

figyrack: Rotor DC: reuse madc casy
(Imagen cortesia de ROTOR, www.

figura 7
Proyecto:Rotor DC: reuse made casy
(Imagen cortesia de ROTOR, www.
rotordborg)
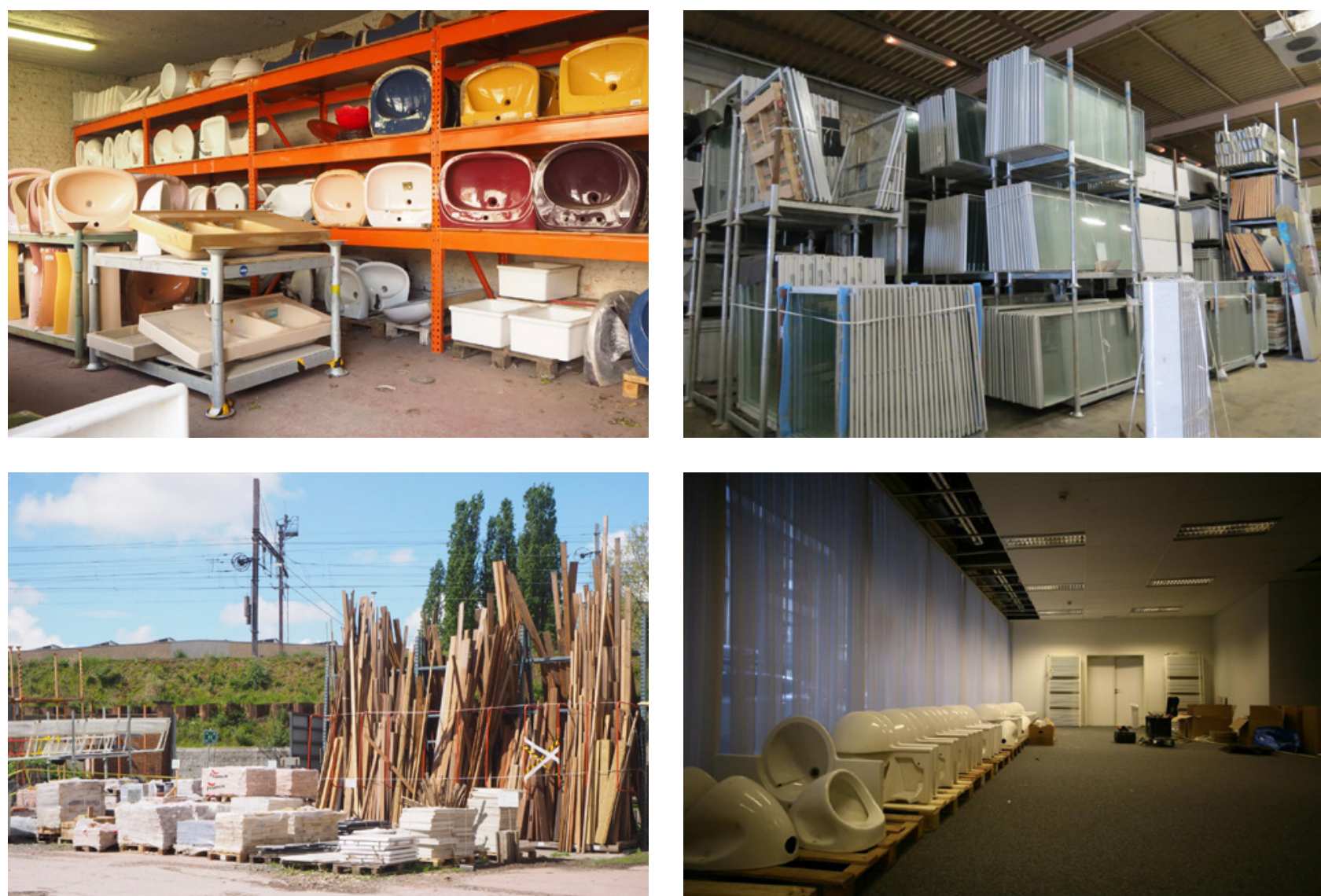

figuras $9,10,11$ y 12

Proyecto: Rotor DC: reuse made casy
(Imagenes cortesia de ROTOR, www
rotordborg)

Ángela Carvajal Fernández

itectura (MARQ) de la Pontificia de Chile (2021). Arquitecta de la Universidad del Valle, Colombia (2012). Socia co-fundadora de Anagramma Arquitectos. Sus intereses se centran en diversos campos de la disciplina, el proyecto como lo construido pero también desde la investigación, representación y teoría
Bibliografía

Cairns, S. Jacobs, Jane (2014). Buildings must die: a perverse

Donoso, Pedro (2016). 'Jane Crawford/ Diálogos' en Gordon Matta-Clark: Experience becomes the object. Barcelona: Ediciones Polígrafa, 2016. Pp, 119.

Lynch, Kevin (2005). '¿En qué consiste el deterioro?' en Echar a perder. Un análisis del deterioro. (2 Ed.) Barcelona: Editorial Gustavo Gilli, 2005. Pp, 155-174.

Melvin, Jeremy (1994). 'Learning to love the fourth dimension' en Building Design No. 1175 (Conferencia por Cedric Price en la AA 'Designing for doubt, delight and demolition - the architect's duty to society). Londrés, Junio 3, 1994. Pp, 24. view of architecture. Canadá: MIT Press, 2014. Pp, 29. 